\title{
Jornalismo colaborativo e redes sociais
}

\section{no mainstream: estudo comparado do jornal zerohora.com e do washingtonpost.com ${ }^{\mathbf{1}}$}

\author{
Anelise Rublescki
}

Eugenia Barichello ${ }^{3}$

1 Uma versão preliminar do artigo foi apresentada no X Lusocom, GT de Jornalismo realizado em setembro/2012, em Lisboa - Portugal, com o título "O jornalismo colaborativo e as redes sociais como estratégia de visibilidade e legitimação dos webjornais na nova ecologia midiática: estudo comparado do jornal zerohora.com e do washingtonpost.com.

2 Jornalista, doutora em comunicação e informação (UFRGS), Pós-doutoranda no Programa de pós-graduação em comunicação da UFSM. Bolsista Capes- Fapergs. anelise_sr@hotmail.com.

3 Professora do Programa de pós-graduação em comunicação da UFSM. Doutora em comunicação pela UFRJ. Bolsista PQ2 do Conselho Nacional de Pesquisa (CNPq). eugeniabarichello@gmail.com. 


\section{Resumo}

O artigo discute o jornalismo colaborativo pela ótica dos conglomerados de mídia. Demonstra que tanto a colaboração do leitor nos espaços dos jornais quanto a intensa inserção das publicações nas redes sociais constituem-se de estratégias de visibilidade e legitimação dos conglomerados na nova ecologia midiática. Metodologicamente, tratase de um estudo que concilia revisão da literatura e empirismo, a partir do estudo comparado entre dois webjornais do mainstream: zerohora. com e washingtonpost.com.

\section{Palavras-chave}

Jornalismo, jornalismo colaborativo, ecologia midiática.

\section{Abstract}

The article discusses the collaborative journalism through the lenses of media conglomerates. It demonstrates that both the reader's collaboration posted in news websites and the intense growth of publications on social networks constitute strategies of visibility and legitimacy used by the conglomerates in the new media ecology. Methodologically, the present studies combines literature review and empiricism, performing a comparative study between two web journals of the mainstream: zerohora.com and washingtonpost.com.

\section{Keywords}

Journalism, collaborative journalism, media ecology. 
No Brasil, é a partir de meados dos anos 1990 que os fenômenos mundiais da digitalização e da convergência se ampliam na sociedade, com a mudança do paradigma industrial para o informacional. Através das conexões em rede, a sociedade brasileira passa a conviver com uma nova rede técnica (o ciberespaço), com novas formas de organização social e de sociabilidades online, a cibercultura ${ }^{4}$, (re)configurando as práticas comunicacionais contemporâneas.

Para o jornalismo, de um modo geral, a expansão da internet comercial proporciona novas práticas no âmbito das empresas midiáticas consolidadas, com o início da disponibilização de notícias online, em $1995^{5}$. Menos do que uma ruptura, aparentemente tratava-se apenas de um novo suporte, onde os conglomerados manteriam o rumo seguro desde a penny press: a transmissão de informações para um público massivo, o mais amplo possível, para atrair anunciantes.

Um breve olhar sobre McLuhan (2005) já demonstra o paradoxo: mesmo que a clássica formulação do autor de que o "meio é a mensagem" possa ser considerada excessiva ou demande problematizações em uma plataforma multimídia como a web, o suporte nunca será um mero condutor de mensagens. Se os formatos jornalísticos são resultantes de modelos históricos de desenvolvimento da cultura, da política, da economia e da tecnologia, não chega a ser surpreendente que a internet altere a produção, a circulação e o consumo das notícias. É sob este olhar que devem ser pensadas as novas características que permeiam o jornalismo líquido (RUBLESCKI, 2011) onde, entre outros fenômenos, a midiatização ${ }^{6}$ crescente de práticas sociais alarga as fronteiras do campo jornalístico com plurais manifestações noticiosas online.

4 Na Comunicação, entende-se por ciberespaço o conjunto de redes que propicia a interação mediada por computador. Já a cibercultura caracteriza-se principalmente pelas apropriações sócio-midiáticas da técnica. Inicia-se (em termos mundiais) ainda nos anos 1950, com a informática e a cibernética, populariza-se através dos microcomputadores na década de 1970, consolida-se nos anos 1980 através da informática de massa, tornando-se expoente a partir dos anos 1990, com o surgimento das tecnologias digitais e com a popularização da internet (LEMOS, 2002).

$5 \quad$ O primeiro site jornalístico brasileiro foi o do Jornal do Brasil, criado em maio de 1995.

6 Trata-se da intensificação de processos que vão transformando tecnologias em meios de produção, circulação e recepção de discursos. Também denominada de cultura midiática, cultura da mídia ou mediatização. 
Nesse cenário, observa-se a configuração de um sistema comunicacional integrado por conexões e nós, caracterizado por um fluxo permanente de comunicações midiáticas e de interações entre usuários, ruptura das categorias sociais do tempo e do espaço, pela digitalização e pela convergência.

Digitalização e convergência propiciam uma significativa diferença entre os meios tradicionais e a ecologia midiática atual: a interatividade. Como diferenciação das mídias tradicionais - jornais, revistas, programas de televisão e de rádio - citam-se os celulares, os palms, os computadores de mesa ou notebooks que, quando conectados à internet ou às redes de telecomunicações, apresentam-se como novas mídias, potencialmente convergentes e interativas. Interativas porque, ao contrário dos meios tradicionais que permitem somente o recebimento de mensagens (modelo um para todos), as novas mídias emergem como dialógicas (um para o outro), bem como, ao menos em tese, de todos para todos, já que são fontes de geração de mensagens coletivas.

Na ecologia midiática atual, as mídias digitais e as redes sociais que estas abrigam, as diversas possibilidades de conexão e de comunicação em rede, associadas a questões de velocidade, leveza e agilidade passam a funcionar em sinergia sistêmica com os dispositivos midiáticos tradicionais. As notícias, que tinham um lugar material de existência (jornais, revistas, televisão), passam a ocorrer também em fluxos informacionais sistêmicos, caracterizados pela porosidade das instâncias leitor-jornalista-fonte e pela intensificação da comunicação tecnologicamente mediada.

Tem-se um sistema complexo que engloba alterações em todos os subsistemas e, dentro destes, em suas respectivas conexões, fluxos e configurações, que alguns autores denominam como a sociedade midiatizada (FAUSTO NETO, 2008). Ou, ainda, como cenário de uma nova ambiência, como o faz Sodré (2002), quando aponta a conformação de um novo bios, ou um 
quarto âmbito existencial: o "bios midiático" ou "virtual", um novo modo de presença do sujeito no mundo?

Trata-se de um "ecossistema de novas mídias" (BOWMAN; WILLS, 2003) ou da "ecologia das novas mídias" (DEUZE, 2006b) que está tomando forma. A dicotomia inicial entre "velhas" e "novas" mídias já soa inadequada, na qual o tom da mudança parece ser "junto a". Nela, os fluxos colocam em evidência a própria processualidade, ou seja, as relações que têm lugar entre os diversos espaços jornalísticos que se apresentam on e offline.

À luz dessa nova ecologia midiática, que desequilibra o clássico binômio produção-recepção de notícias verticalmente mediadas por jornalistas e que transfere a tônica para a circulação das notícias, o artigo discute o webjornalismo colaborativo praticado no âmbito dos conglomerados e a inserção desses nas redes sociais como estratégia de visibilidade e legitimação. Metodologicamente, trata-se de um estudo teórico-analítico que concilia revisão da literatura e empirismo, a partir do estudo comparado entre dois webjornais do mainstream: zerohora.com ${ }^{8}$ e washingtonpost.com ${ }^{9}$.

\section{Redes sociais: filtros e recomendação de leitura}

A web 2.0 significa, por princípio, interatividade e, como consequência, geração de conteúdo também pelo usuário. É a partir de então que a porosidade entre jornalista, leitor e fonte - que tensiona a mediação jornalística e a processualidade das notícias - se torna mais visível, especialmente a partir do crescimento da blogosfera $^{10}$ e das redes sociais, do jornalismo colaborativo e

7 O quarto bios se somaria aos três bios aristotélicos: conhecimento, prazer e política.

8 http://zerohora.clicrbs.com.br

9 http://www.washingtonpost.com/

10 A blogosfera é definida por Orihuela por "ser um espaço anárquico, desierarquizado, informal e descentralizado onde convergem a multiplicidade de culturas, comunidades e tradições para gerar de forma coletiva, distribuída e espontânea informação, opinião e conhecimento" (ORIHUELA, 2008). 
dos sites de webjornalismo participativo ${ }^{11}$. Estas iniciativas estão entre as que mais crescem na web.

Trata-se de um jornalismo desvinculado dos meios de comunicação tradicionais, não necessariamente com o intuito de competir com estes; embora o façam, no mínimo, quanto ao tempo e a atenção do leitor, dois bens escassos e não renováveis. Um jornalismo que, eventualmente, pode ser feito por qualquer pessoa (individualmente), por entidades coletivas de interesse social (associações comunitárias, entidades filantrópicas, sindicatos, organizações não-governamentais), por organizações de comunicação independentes (Slashdot, OhmyNews). São iniciativas que se referem, sobretudo, às funções pós-massivas (RUBLESCKI, 2011, p. 44).

Essas possibilidades de colaboração abertas na rede instituem o público como agente inovador de ferramentas e produtos dos mais variados gêneros - inclusive de viés noticioso. Para Chris Anderson (2006, p.81), o que se pode afirmar é que "a linha tradicional entre produtores e consumidores tornouse menos nítida", sustentando que a ação complementar de profissionais e amadores na rede estabelece o chamado movimento Pro-Am ${ }^{12}$. Pensando-se especificamente em termos do sistema jornalístico, trata-se da porosidade entre as instâncias produtoras de conteúdo, uma das características centrais da nova ecologia midiática. Significa dizer que, no cenário atual, os conglomerados midiáticos não competem apenas entre si, mas também com as informações que circulam online.

11 Há uma pluralidade de denominações, frequentemente utilizadas como sinônimo, mas que guardam diferenciações entre si. As mais comuns seriam jornalismo participativo, jornalismo colaborativo e jornalismo open source. Jornalismo participativo ocorre, por exemplo, nas matérias publicadas por veículos de comunicação que incluem comentários dos leitores. Os comentários somam-se aos artigos, formando um conjunto novo. Dessa forma, leitores participam da notícia. Por outro lado, o jornalismo colaborativo é usado quando mais de uma pessoa contribuiu para o resultado final do que é publicado. Pode ser um texto escrito por duas ou mais pessoas ou ainda uma página que traga vídeos, sons e imagens de vários autores. Finalmente, dá-se o nome de jornalismo open source ao jornalismo feito em sites wiki, que permitem a qualquer internauta alterar o conteúdo de uma página. Também pertencem a esse grupo vídeos, fotos, sons e textos distribuídos na rede com licença para serem alterados e retrabalhados (FOSCHINI; TADDEI, 2006). 
O que o surgimento de novos players no ciberespaço propõe aos produtores formais de informação é ruptura do predomínio do pólo de emissão, um impacto que vai além da inclusão de um novo suporte e meio de distribuição (a web) e do tempo real, colocando em risco a viabilidade financeira do negócio. No mundo 2.0, a informação e conversação independem das fontes formais, permitindo alto grau de envolvimento e personalização por parte dos usuários e uma articulação coletiva baseadas na concentração, no mesmo ambiente digital, de ferramentas de produção de conteúdo e de participação e diálogo. O mundo 2.0 apresenta, portanto, uma inversão de papéis inusitada: os usuários - tidos sempre como clientes - assumem a posição de concorrentes (CORRÊA; LIMA, 2009, p.26).

Compactua-se com Barichello e Carvalho (2011, p. 266) quando afirmam que "essa possibilidade de acesso direto à informação por parte dos atores sociais representa uma crise de legitimação às instituições que têm a mediação como papel central, como é o caso do jornalismo". Para as autoras:

A legitimação é um processo constante de justificação e explicação de uma ordem institucional. É para buscar ou manter reconhecimento da sociedade que a instituição precisa de mecanismos de legitimação. A legitimação renova um campo já institucionalizado, garantindo sua permanência e mantendo coeso um universo de significação (BARICHELLO; CARVALHO, 2011, p.269).

Na ecologia midiática que ora se configura, os conglomerados midiáticos adotam variadas estratégias de visibilidade em busca de legitimação. Dentre elas, duas se referem à questão central desse artigo: a colaboração do interagente no "espaço do jornal" (que, na realidade, já existia na forma de cartas e telefonemas à redação, por exemplo) e que agora se manifesta também pelo webjornalismo colaborativo e a interatividade com o leitor através das mídias e redes sociais, isto é, o conglomerado nos "espaços do leitor", que abordamos a seguir. 


\section{Mídias e redes sociais: o jornalismo tradicional no espaço do leitor}

No cenário atual, já não basta dar a notícia: é necessário que ela circule e seja recomendada. As empresas jornalísticas também já perceberam a importância do fenômeno e passaram a utilizar ferramentas que nasceram como micromídias, gerando uma maior aproximação entre os veículos tradicionais e as redes sociais. A exemplo dos blogs e micromídias digitais de livre compartilhamento, qualquer página de notícias de sites ou portais jornalísticos agrega botões de compartilhar (com os símbolos do Twitter e do Facebook), recomendar, curtir. Trata-se de um mecanismo de visibilidade, já que as redes sociais cada vez mais funcionam como uma rede de informações que filtra, recomenda, discute e qualifica a informação e as notícias que circulam na internet. Além disso, os próprios conglomerados de mídia estão entre as empresas que mais utilizam plataformas como o Twitter diariamente.

O levantamento de dados para este artigo contemplou a semana de 23 a 30 de maio de 2012, escolhida de forma aleatória. O jornal zerohora. com enviou uma média de 53 tweets por dia e o washingtonpost.com, 64. O potencial de alcance, filtragem e recomendação desses tweets pode ser avaliado a partir de diversos indicadores, sendo o mais básico deles o número de seguidores. As figuras 1 e 2 evidenciam o número de seguidores nos jornais online objeto da pesquisa. Partimos, para fins de comparação, de afirmativas como as de Recuero (2009) de que a maioria dos perfis sociais na rede tem 50 ou menos seguidores ${ }^{13}$.

13 Neste artigo não serão aprofundadas questões relevantes que diferenciam o Brasil e os Estados Unidos em termos de infoinclusão social. Entende-se no trabalho que, em seus respectivos países, ambos os webjornais possuem boa visibilidade online. 


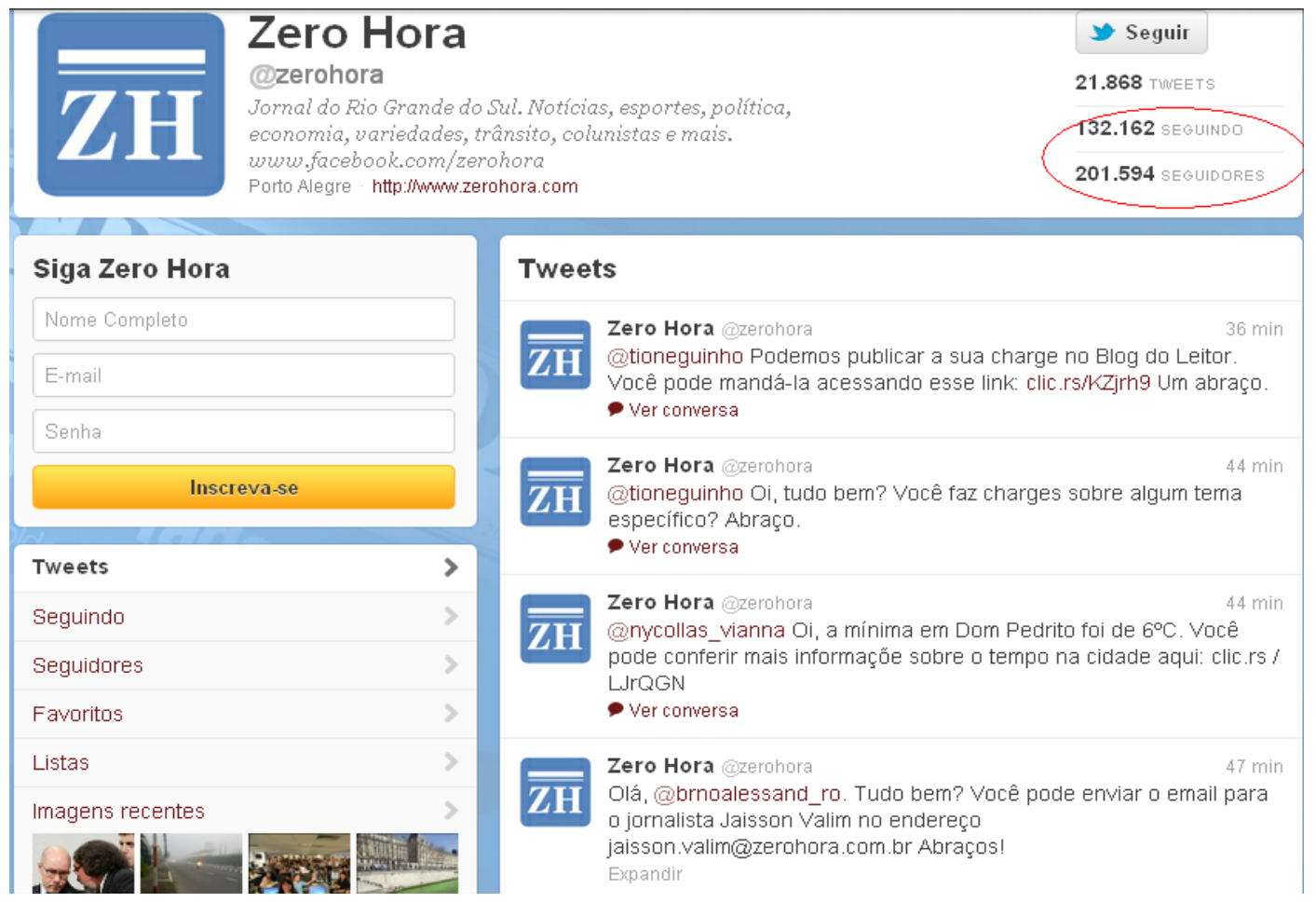

Figura 1: Twitter do zerohora.com

Fonte: http://twitter.com/zerohora

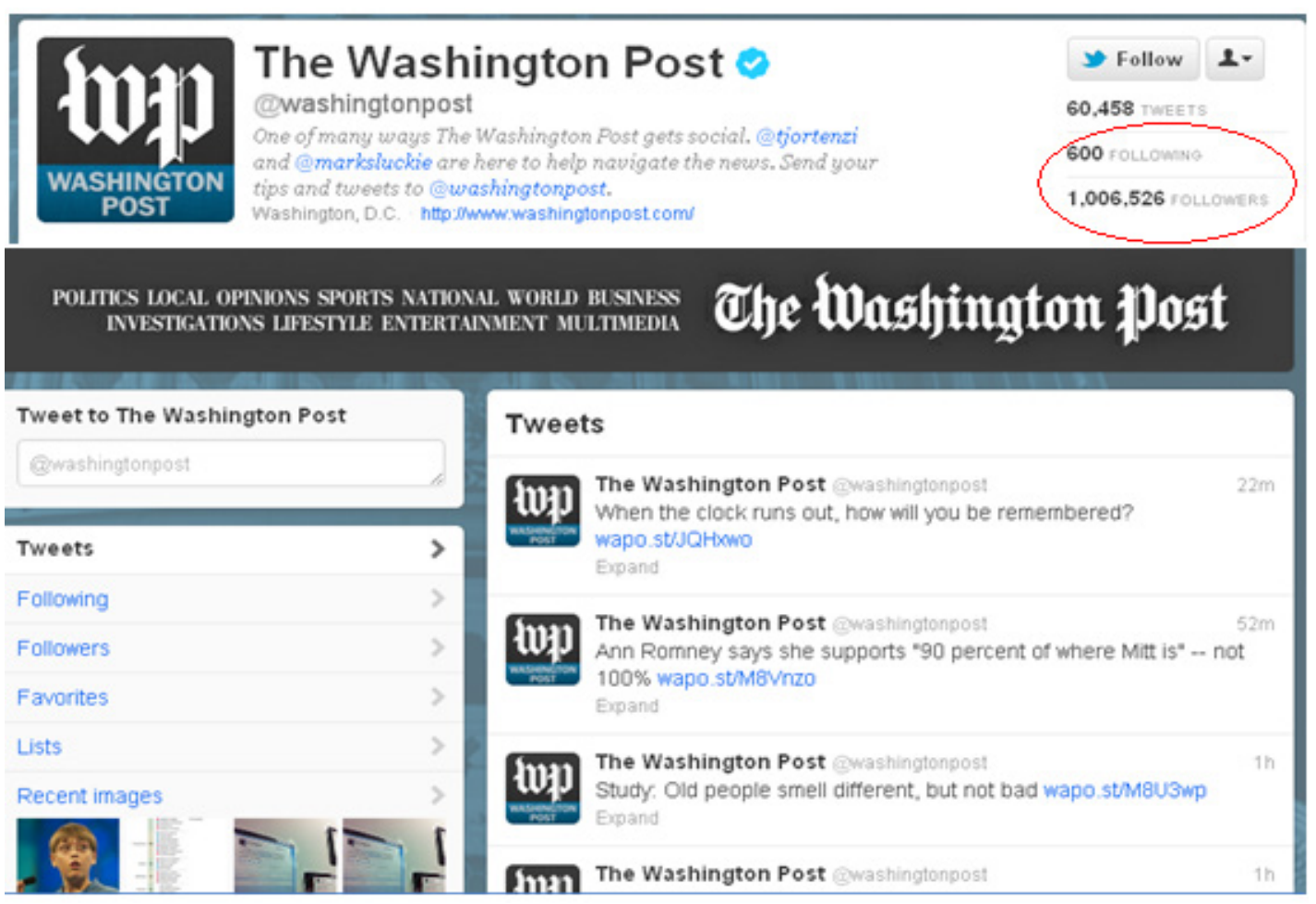

Figura 2: Twitter do washigntonpost.com

Fonte: http://twitter.com/washingtonpost/ 
Observa-se que as atualizações do Twitter nos dois jornais seguem a lógica do tempo real, onde cada nova postagem no site gera um tweet. Em essência, cumprem a mesma função informativa dos teasears ${ }^{14}$ e dos títulos: buscam captar a atenção, direcionar e fomentar a leitura da matéria na íntegra, através do simples clique no link de um tweet. Trata-se, também, de estratégias de visibilidade que buscam não apenas a leitura das notícias nos sites, mas a própria legitimação da organização no cenário midiático pelo endosso do interagente, através do compartilhamento. Como uma rede social se comunica com outras, não apenas do mesmo site, mas também com outras mídias sociais (Twitter e Orkut, por exemplo), configura-se o efeito multiplicador da postagem pelos veículos.

Há autores que veem no processo um mecanismo para lidar com a avalanche informativa, transferindo para as comunidades a tarefa de triagem da profusão de notícias e informações que hoje circulam na web. Para outros, posição que se defende neste artigo, é justamente aí que ainda reside a força do jornalismo no cenário atual. Em meio à avalanche informativa e apesar da possível constatação ligeira de que os leitores têm contato direto com os fatos do cotidiano, não há indicações de que os interagentes prescindam da presença das empresas jornalísticas nas funções de mediação e interpretação dos conteúdos nele. São funções sociais usualmente associadas às instituições legitimadas socialmente, mesmo que estas estejam em pleno processo de adaptação à nova configuração midiática, que inclui também as micromídias digitais. Neste sentido, uma iniciativa pioneira partiu também do washigntonpost.com, que passou a utilizar a plataforma Facebook, não apenas como página institucional ou fan page, como fazem tantas organizações, mas para veiculação de notícias.

14 O termo teaser refere-se ao trecho de texto que é apresentado antes da tag "leia mais", devendo o leitor clicar em um link ao final do teaser para ter acesso ao texto completo. Este recurso normalmente é usado para permitir que o leitor acesse somente os textos que lhe interessam, sem ter que carregar para seu computador conteúdos que não pretende ler ou visualizar, poupando tempo de download e tráfego de internet. 


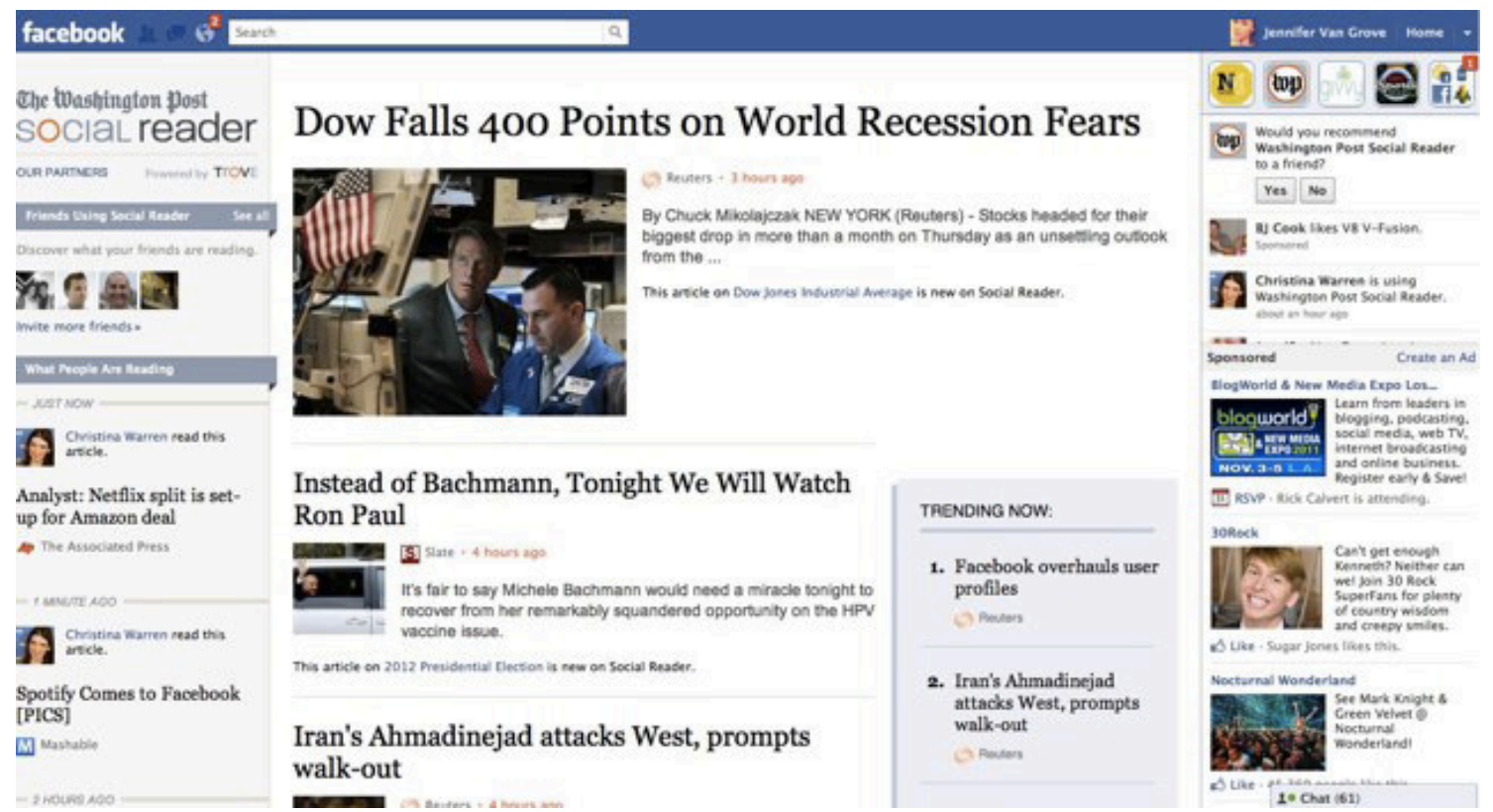

Figura 3: Aplicativo de notícias do washigntonpost.com no Facebook Fonte: http://pt-br.facebook.com/washingtonpost

O recebimento das notícias pode ser personalizado pelo interagente, limitando-o às temáticas que mais Ihe interessam. Ao clicar em What people are reading, o usuário tem o retorno das notícias mais acessadas e, se optar Friends using social reader, verá o que os seus amigos do Facebook estão lendo. Trata-se da adoção da lógica das redes sociais pelo washigntonpost. com, já que, como afirma Donald Graham (2012), presidente-executivo do Facebook, "se você sabe que vários dos seus amigos estão lendo uma história, você fica mais interessado nela".

Mas não é apenas pela adesão às mídias sociais digitais que os jornais do mainstream buscam visibilidade e legitimação junto ao leitor. As redações investem também no webjornalismo colaborativo, uma nova forma de participação possível do leitor no espaço dos webjornais, para além de cartas e telefonemas às redações. 


\section{A participação do leitor nos espaços do jornal}

O jornalismo em colaboração enriquece as notícias especialmente por dois vieses. Por um lado, os blogs e as mídias digitais potencializam a produção de informações jornalisticamente relevantes a partir de múltiplos atores/ interagentes. Por outro, o jornalismo em colaboração caracteriza-se também pelos comentários e, principalmente, pelos links que possibilitam uma interligação entre fragmentos de complementação que, juntos, configuram uma maior carga informativa à postagem original. São alterações que permeiam a internet de modo geral e, pelo viés deste artigo, também as empresas jornalísticas.

Com relação à colaboração do leitor nos "espaços do jornal", com material de viés noticioso online, salientamos que foi a própria sociedade que a conquistou, pela combinação de fatores relevantes para os conglomerados de mídia. Em primeiro lugar, os sites colaborativos-participativos e de discussão e comentários cresciam rapidamente, em uma iniciativa que acontecia à margem da grande imprensa. Para Malini (2008), os grandes jornais online decidiram se abrir à participação dos usuários como:

(...) forma de trazer os conteúdos circunscritos a blogs e sites independentes, que, com frequência, gera audiência e complementa as informações dos jornais online. Além disso, dá mais capilaridade a estes, tornando-os ainda mais local, à medida que boa parte do noticiário se concentra em notícias locais e opiniões sobre temas de forte apelo público (MALINI, 2008, p. 11).

Em segundo lugar, os próprios interagentes começaram a enviar espontaneamente material para as redações, tornando-se fontes valiosas de dados e imagens em lugares onde a imprensa não estava. Um dos já muitos exemplos mundiais foi a explosão nos tanques de petróleo de Buncefield, ocorrida nas primeiras horas da manhã de 11 de dezembro de 2005 a cerca de 40 quilômetros de Londres, que gerou uma resposta sem precedentes por parte dos cidadãos enviando milhares de e-mails, fotos e videoclipes sobre o desastre 
para os sites de notícias muito antes da chegada de jornalistas profissionais ao local da explosão. Apenas a BBC recebeu mais de 6.500 e-mails, começando desde os primeiros minutos após a explosão (RUBLESCKI, 2009).

Iniciativas como esta motivaram os jornais brasileiros a também criar espaços para a publicação de material enviado pelos leitores. Do ponto de vista institucional, o veículo investe na interatividade e na aproximação com seu leitor. Como mídia, obtém material de situações onde nenhum repórterfotógrafo estava presente. Trata-se, contudo, de uma clara inversão de papéis do jornalismo líquido já que, historicamente, sempre coube à imprensa estar presente e noticiar o quê o leitor não sabia e de onde não podia estar.

Em casos de catástrofes e calamidades, as empresas jornalísticas se beneficiam, especialmente, de fotos e vídeos enviados pelos interagentes. Foi o que ocorreu, por exemplo, na tragédia natural que assolou o Japão em março de 2011, a partir do maior terremoto da sua história. No primeiro dia, o zerohora.com recebeu centenas de contribuições. No dia a dia das redações, o que a observação conduzida para este artigo evidenciou é que os espaços reservados aos leitores nos conglomerados de mídia brasileira ainda são fortemente delimitados, tanto gráfica, quanto editorialmente. As contribuições são mediadas, limitadas visualmente no "Leitor-Repórter - canal de jornalismo colaborativo"15, também referenciado dentro da edição como "blog do leitor".

A interatividade, certamente uma das esperanças dos conglomerados de mídia para competir na estrutura social emergente, é ainda, do ponto de vista das empresas jornalísticas profissionais no Brasil, um conceito tentativo, que envolve mais promessas do que desempenho (RUBLESCKI, 2010). Como exceção temos alguns dos blogs dos jornalistas-colunistas, em que o nível de interação dos - e com - os leitores é bastante superior ao das seções colaborativas dos principais jornais de referência. 
Contudo, há claramente uma tendência de crescimento do jornalismo em colaboração como decorrência natural da própria expansão da web. Há também a perspectiva de que, gradualmente, se desenvolva uma maior experiência colaborativa por parte dos interagentes e uma maior flexibilidade por parte das empresas midiáticas, que, efetivamente, constituam o jornalismo de aprofundamento em colaboração.

Algumas das publicações mais tradicionais na imprensa mundial de jornalismo já estão buscando uma nova relação com os leitores pelo viés do jornalismo colaborativo.

Enquanto a maioria dos jornais encara a questão dos comentários de leitores como uma dor de cabeça permanente, o Post [The Washigton Post] decidiu transformar a participação do público no seu objetivo estratégico na guerra por audiência no disputadíssimo mercado de oferta de informações na internet. O novo modelo de publicação de comentários de leitores na página Web do jornal é inédito na internet, custou vários milhares de dólares e cria um padrão novo em matéria de relacionamento entre jornalistas e o público (CASTILHO, 2009, online).

Por um lado, o jornal passou a realmente incentivar as postagens dos interagentes, dando-Ihes destaque, como demonstra a figura em sequência (Figura 4). Nela observamos, logo abaixo do título e do lead reduzido da notícia, o convite para que se envie comentários, junto com a sinalização de quantos interagentes já enviaram a sua colaboração, atualizada sempre em tempo real. 


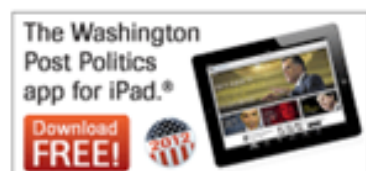

In the News DocWatson LoriAnne Madison Spain Manhattanhenge 'Les Miserables' Accoun

\section{As governor, Rommey shifted on judgeships}
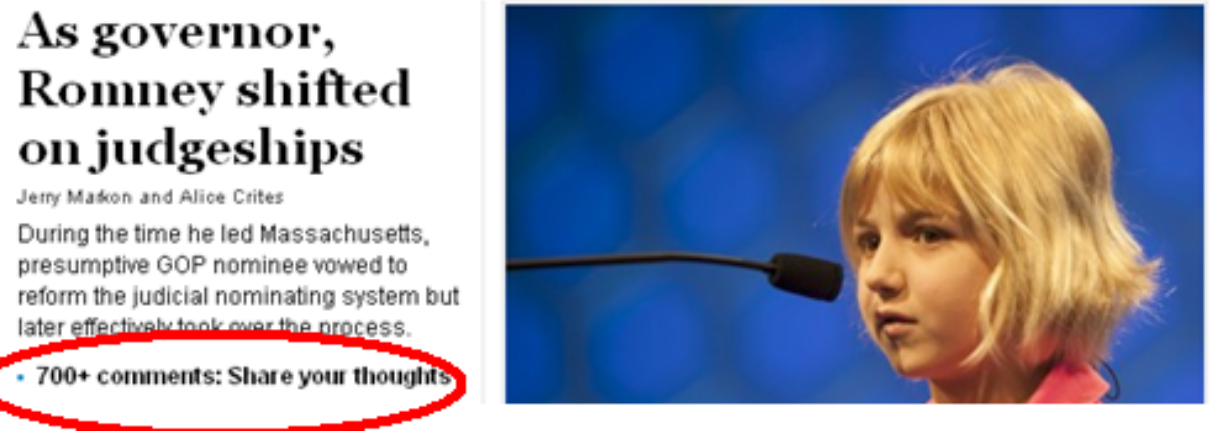

Figura 4: Homepage do The Washigton post incentiva comentários Fonte: The Washigton post, homepage em 30/5/2012, 22h.

Verifica-se que a participação incentivada pelo jornal difere do que ainda é praticado no Brasil de modo geral e no zerohora.com em particular, onde a tônica da participação gira em torno do envio de material, especialmente vídeos ou fotos de situações presenciadas pelo interagente. O que o washigtonpost. com busca e que tende a ampliar as fronteiras do jornalismo através das colaborações é o aprofundamento do conteúdo e o estreitamento das relações, não apenas da redação com os leitores, mas também dos debates entre os interagentes. Ao menos é o que se infere de duas outras novidades que foram introduzidas pelo veículo. A primeira permite a visualização fácil da relevância relativa de cada comentário em função das referências recebidas de outros interagentes, incentivando o relacionamento entre leitores, mais do que entre eles e a redação (Figura 5). 


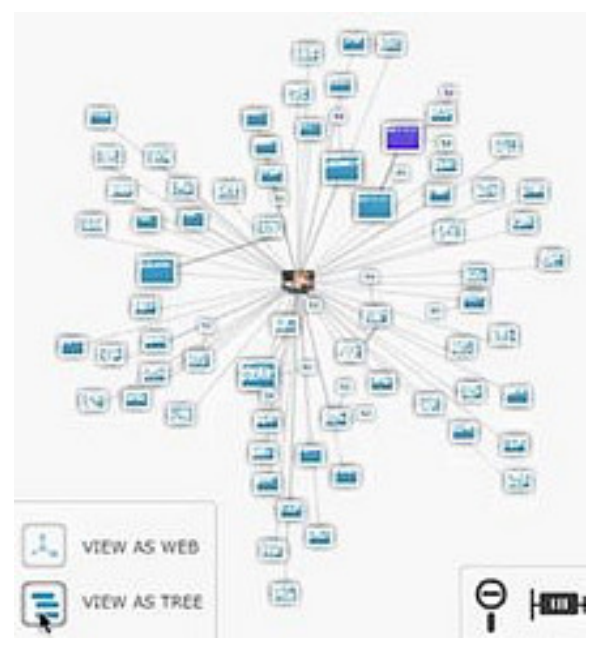

Figura 5: Formato visual dos comentários do The Washigton post Fonte: CASTILHO, 2011.

Na figura, os retângulos maiores são dos textos mais comentados e citados por leitores. Os quadros mais próximos do centro pertencem aos temas mais lidos, mas não necessariamente os mais comentados. Concorda-se com o autor quando ele pontua que esta organização visual constitui "um enorme avanço em relação ao sistema usual", em que as participações de leitores são publicadas em ordem cronológica inversa e sem uma segmentação por tema.

O sistema do washigntonpost.com estimula a participação entre os interagentes e potencializa as interações e os debates, pois torna possível perceber rapidamente quem está discutindo o quê e com quem, na área de comentários. É um formato que propicia que o jornalismo em colaboração aprofunde a notícia.

Outra iniciativa pioneira também partiu da versão on-line do The Washington Post, que introduziu, em março de 2011, um formulário ${ }^{16}$ para que os leitores informem erros nas notícias do Jornal. Segundo dados do próprio veículo, nos 15 primeiros dias de funcionamento foram recebidas 540 participações no formulário, sendo 180 referentes a links quebrados, erros de ortografia ou em legendas das fotos. Trinta e dois avisos apontaram informações 
errôneas no conteúdo de notícias publicadas no jornal online. Os avisos postados no formulário são enviados diretamente para chefes das editorias, responsáveis por checar os informes dos leitores e interagir com eles.

Por fim, merece destaque também uma outra estratégia recentemente adotada também pelo washigntonpost.com, na qual o jornal passou a construir notícias a partir dos relatos ou opiniões dos interagentes ${ }^{17}$. São textos que sempre iniciam com a expressão "Segundo o leitor..." e que extrapolam ao mero uso de fotos fornecidas pelos interagentes em situações onde nenhum repórter estava presente.

\section{Considerações finais}

Efetivamente, no atual ecossistema midiático, há uma ampliação da esfera midiática onde blogs, redes sociais e sites de jornalismo não-tradicionais aumentam a circulação e a visibilidade das notícias também dos veículos consolidados, criando uma espécie de segundo mercado para este material informativo. Paralelamente, as redes sociais e as micromídias digitais que as abrigam passam a ser amplamente utilizadas também pelos jornais de referência em busca de visibilidade e legitimação.

A colaboração do usuário no webjornalismo consolidado vai sendo aceita gradualmente pelos próprios conglomerados na medida em que solicitam e se valem da cobertura noticiosa dos interagentes em situações pontuais ou quando utilizam sites diversos como parte da apuração ou da geração de pautas. Por ora, no entanto, persiste a prática da compartimentalização, em que o aproveitamento do conteúdo fornecido pelo interagente é delimitado de forma gráfico-editorial. No aprofundamento do processo deste novo jornalismo, a tendência é que as fronteiras entre os subsistemas jornalísticos se tornem mais tênues. 
Isto porque o jornalismo online tende a funcionar como um pacto implícito entre um novo tipo de autor e um novo tipo de leitor. Na atual ecologia midiática tende a diminuir o leitor contemplativo enquanto cresce a presença daquele leitor que entra nos espaços do jornal e que, ao invés de apenas telefonar para as redações ou enviar cartas ao editor do jornal, critica, comenta, produz, recomenda notícias.

Trata-se de uma mudança comercialmente estratégica e também cultural, cujo estágio ainda é embrionário no zerohora.com e um pouco mais evoluído no washigtonpost.com, ao incentivar a interação e os comentários aos post dos próprios interagentes. O sistema de visualização que organiza este diálogo entre os interagentes é um bom modelo a ser seguido. A linha divisória jornalleitor segue existindo, mas já é um segundo estágio em direção a um jornalismo colaborativo que, efetivamente, mereça essa denominação. 


\section{Referências}

ANDERSON, C. A cauda longa: do mercado de massa para o mercado de nicho. 6a ed. Rio de Janeiro: Elsevier, 2006.

BARICHELLO, E.; Carvalho, L. "Jornalismo e Mídias Sociais Digitais: transformações no processo de legitimação institucional no serviço de micromensagens twitter". I Colóquio Internacional Mudanças Estruturais no Jornalismo (MEJOR). Brasília. Anais do I Colóquio Internacional Mudanças Estruturais no Jornalismo (MEJOR). Brasília: UnB, 2011. v. 1. p. 1-15.

BOWMAN, S.; WILLIS, C. We Media: how audiences are shaping the future of news and information. Reston (EUA): Media Center at American Press Institute, 2003.

CASTILHO, C. "Jornalistas usam cada vez mais blogs e redes sociais como fonte informativa". Observatório da Imprensa. On-line, 2010. Disponível em: <http:// carloscastilho.posterous.com/jornalistas-usam-cada-vez-m-ais-blogs-e-redes >. Acessado em: 3 mar. 2011.

Novo leitor em um novo mundo. 2009. On-line. Disponível em: <http://www. oxisdaquestao.com.br/integra_integra.asp?codigo=383 >. Acessado em 12 mar. 2011.

CORRÊA, E.; LIMA, M. "O impacto das mídias sociais nas empresas informativas: transformações no processo produtivo". In: BRITTOS, Valério (org.). Digitalização e práticas sociais. São Leopoldo: Editora Unisinos, 2009.

DEUZE, M. "O jornalismo e os novos meios de comunicação social". Comunicação e Sociedade. São Bernardo do Campo: UMESP, v. 9-10, n. 1, 2006. p. 15-37.

FAUSTO NETO, A. "Midiatização: a influência nos novos e nos clássicos meios de comunicação". Cadernos IHU (Unisinos), v. 1, p. 2008, p.1-16.

FOSCHINI, A. C.; TADDEI, R. Jornalismo cidadão: você faz a notícia. Coleção Conquiste a rede. On-line, 2006. Disponível em: <http://www.anacarmen.com/download/ conquiste-a rede/Conquiste_a_Rede_Jornalismo_Cidadao.pdf >. Acessado em: 12 ago. 2010. 
GRAHAM, D. When Zuckerberg Met Graham: A Facebook Love Story. The Wall Street Journal. On-line. 5 jan 2012. Disponível em; http://online.wsj.com/article/SB10001424 052970203686204577116631661990706.html. Acessado em: 8 set. 2012.

LEMOS, A. Cibercultura, tecnologia e vida social na cultura contemporânea. Porto Alegre: Sulina, 2002.

MALINI, F. "Modelos de colaboração nos meios sociais da internet: uma análise a partir dos portais de jornalismo participativo". XXXI Congresso Brasileiro de Ciências da Comunicação. Anais. Natal: Intercom, 2008.

McLUHAN, M. Os meios de comunicação como extensões do homem. 20a ed. São Paulo: Cultrix, 2005.

ORIHUELA, J. L. "Blogs, jornalismo e tecnologia". Entrevista. Monitor de Mídia, 2008. Disponível em: <http://www.univali.br/monitor>. Acessado em: 18 ago. 2010.

RECUERO, R. "Redes sociais na internet, difusão de informação e jornalismo". In: SOSTER, D.; SILVA, F. Metamorfoses jornalísticas 2: A reconfiguração da forma. Santa Cruz do Sul: Edunisc, 2009.

RUBLESCKI, A. Jornalismo líquido: mediação multinível e notícias em fluxos. Tese de Doutorado. Faculdade de Biblioteconomia e Comunicação da Universidade Federal do Rio Grande do Sul. 2011.

. "A crise de identidade dos jornais impressos". Ícone, v. 12 n.1, ago $2010,1-12$.

- "Jornalismo e Conteúdo Gerado pelo Usuário: uma discussão sobre credibilidade". XXXII Congresso Brasileiro de Ciências da Comunicação. Anais. Curitiba: Intercom, 4 a 7 de set de 2009.

SODRÉ, Muniz. Antropológica do Espelho. Petrópolis, Rio de Janeiro: Vozes, 2002. 